\title{
RESEARCHES ON THE FORMS AND STABILITY OF AËROPLANES.
}

By W. R. Turnbuli.

$\mathrm{T}$

HE crying need to-day of aëronautics (considered as a science) is research work, and it is simply amazing, when one considers the thousands of scientific workers in all parts of the world devoting their time to refinements and ultra-refinements of wellknown physical laws, to note how few persons are willing to take up the laws of aerrodynamics and reduce them to an exact science.

The field that is open is alluring, even fascinating, and there is more scope for original research, and more chance for reward than in many of the beaten tracks; and yet the student of science still holds aloof, preferring to pass and repass over the footsteps of others.

Just as soon as the mechanical engineer can command at his designing table full data concerning the lift, drift and center of pressure of aëroplanes, the thrust and efficiency of different forms of air propellers, the strength and suitability of materials, and the complete elements entering into the longitudinal and transverse stability of an aërodyne, ${ }^{1}$ considered as a whole, just so soon, and not before, can we reasonably expect the problem of aerial navigation to be really solved.

During a careful study of the history of aerrodynes, which I have followed to the time of writing (October, I 906), the fact that has

II use the word "aërodyne" in preference to "flying-machine," to denote an aëroplane-supported machine, driven by mechanical power through the air. I regret the introduction of a new term in the nomenclature of aërodynamics but there is certainly a term lacking to express the required meaning, for "flying-machine" (Ger. Flugmaschine : Fr. machine volante) is too general and too suggestive of a wing-flapping machine; " aëroplane", (Drachenschweber, Fr. aëroplane) should apply not to the whole machine but to the supporting surface only (moreover, aëroplane is used to denote a soaring machine, etc., which is not power-driven) and "aërodrome", (the term used by Langley) while it is euphonious really denotes an air course in the same sense that hippodrome means a course for horse-races. "Aërodrome"" in France is also used to mean a balloonshed (compare Capt. F. Ferber, Revue d'Artillerie, Mars, 1904, also a letter by the writer in The Scientific American, September 22, I906). 
most impressed me is that in every one of the proposed machines, both in the tried and untried ones, automatic longitudinal stability is not only a weak feature of the designs but is altogether absent in practically every case.

To a fairly satisfactory extent automatic transverse stability (by giving the aerroplanes a dihedral angle or by keels) is a solved problem, but not so automatic longitudinal stability. On this account I took up the laboratory study of aëroplanes with the aim clearly in view of finding if possible a type of aëroplane that should have automatic longitudinal stability. In this I have been most fortunate for I have found a type of double curvature aerroplane which not only possesses the elements of automatic longitudinal stability but also gives a very good "lift" and much reduced "drift" when compared with the single curvature surfaces most commonly employed and looked upon as our most efficient lifting aëroplanes.

To make the study systematic let us divide all the possible (simple) aëroplanes into five types as follows :

Type I. The plane surface.

Type II. The single curvature surface, convex on the under side.

Type III. The single curvature surface, concave on the under side (the opposite of type II.).

Type IV. The double curvature surface, concave at the forward portion, convex at the after portion, on the under side.

Type V. The double curvature surface, convex at the forward portion, concave at the after portion on the under side.

These are the only possible types (leaving out multiple curvatures of more than two) and we will take up the study of each individually and then compare the results.

In order to further simplify the problem and to make the results with the five different types strictly comparable with one another, I will deal only with surfaces having a rectangular plan-view and in which the width (at right angles to the air current) is twice the length (in the direction of the air current). While this method fails to cover the whole ground, since the number of possible plan-views is practically limitless, I feel assured that, so far as general lazes are concerned the two-to-one rectangle is fairly typical of all torms.

Throughout the experiments, therefore, the five following planes 
are alone used: See Fig. I, in which the common (developed) planview is shown at $A$ and the various cross-sections along any fore and aft line $a b$ corresponding to the above mentioned types are shown at $B, C, D, E$, and $F$. The arrow gives the direction of the air current.

In each case the (developed) length is 8.485 inches and the width is 16.97 inches, giving a two-to-one ratio with an area of 143.99 square inches or practically one square foot.

These five types were experimented with, first as to their "lifts"

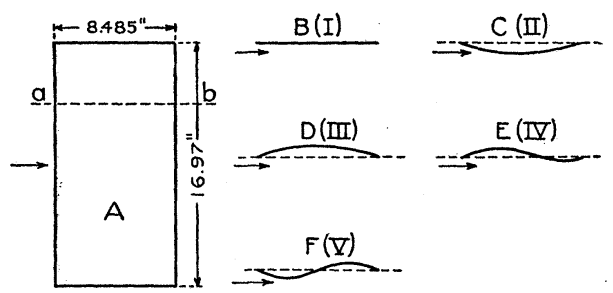

Fig. 1.

from $0^{\circ}$ to $20^{\circ}$, second as to their "drifts" from $0^{\circ}$ to $20^{\circ}$ and third as to their longitudinal stability, or as to the position of the center of pressure at all angles from $0^{\circ}$ to $90^{\circ}$.

\section{Methods and Results.}

General.

It is a well-known fact that the natural wind varies greatly (even from second to second) in intensity ${ }^{1}$ and it is even a difficult matter to obtain an artificial wind that has absolute constancy; in these experiments, therefore, in order that the results may be exactly comparable with one another, the writer employed a heavy 4-bladed fan-propeller to produce a constant air current and this fan-propeller was driven by an electric motor whose current was from a storage-battery of ample capacity. This fan-propeller was mounted at one (open) end of a rectangular box 6 feet long and 22 inches square and the speed of the propeller was so adjusted that the air-current at the opposite (open) end was exactly ten miles per hour at a distance of one foot from the end of the box. In the box near the propeller and for the first half of its length thin "baffle-

${ }^{1}$ Compare Langley, "The Internal Work of the Wind," and others. 
plates" were placed to avoid rotary air currents so that a practically rectilinear air current was produced at the experimental end of the box. The box was further raised from the floor about two feet and this is a most important point in such experiments, for if the box be placed on or near the floor the intake of the fan-propeller is unequal with a consequent inequality at the opposite end of the box.

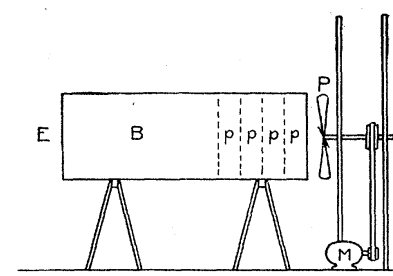

Fig. 2.

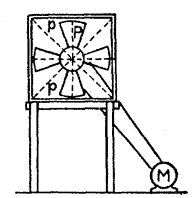

Fig. 3.

Fig. 2 shows a side view and Fig. 3 an end view of the general arrangement of apparatus in all the experiments; in which $M$, is the electric motor ; $P$, the propeller; $B$, the long box ; $p p$, baffle-plates and $E$, the end at which the different apparatus for "lift," "drift" and center of pressure were placed.

The air current used in all the experiments was ro miles per hour, for it was found (as before frequently established) that the "lift" and "drift" of the aëroplanes vary as the square of the speed of the air current, so that it is a simple matter to compute the "lift" and "drift" for any speed (within ordinary limits at least) when the values for a certain speed are known. The variation (if any) for the position of the center of pressure, with different velocity of air currents, was not determined, as the system was not sufficiently flexible to obtain high speeds.

The aëroplanes experimented with were made of thin tin plate with only a sufficient number of ribs (three) on the upper side, to make the forms absolutely rigid.

The original experiments were made in February to April, 1905, and were further repeated with refined apparatus in June and July, I906.

$$
\text { "Lift" Experiments. }
$$

The apparatus for obtaining the "lift" (or vertical component of air pressure) of the aëroplanes, was mounted in such a way that 
the centers of the aeroplanes were one foot from the free end of the box and exactly in the middle of the opening.

Fig. 4 shows a side elevation, and Fig. 5 an end elevation, of

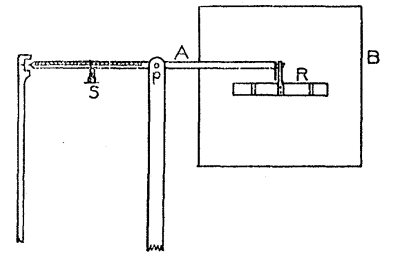

Fig. 4.

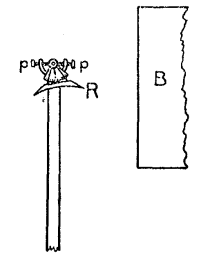

Fig. 5.

this apparatus which is simply a common balance arm, $A$ (mounted on horizontal pivots, $p p$ ), with the aëroplane, $R$, mounted on one arm, and with a movable scale-pan, $S$, on the other arm to measure the loss of weight when the air current passes.

Throughout the experiments the aëroplane, $R$, was inclined at angles of $0^{\circ}, 5^{\circ}, 10^{\circ}, 15^{\circ}$ and $20^{\circ}$ with the horizontal, and the corresponding settings of the scale-pan, $S$, to make a balance when the air current passes, were recorded.

In this way a series of readings were obtained which are plotted

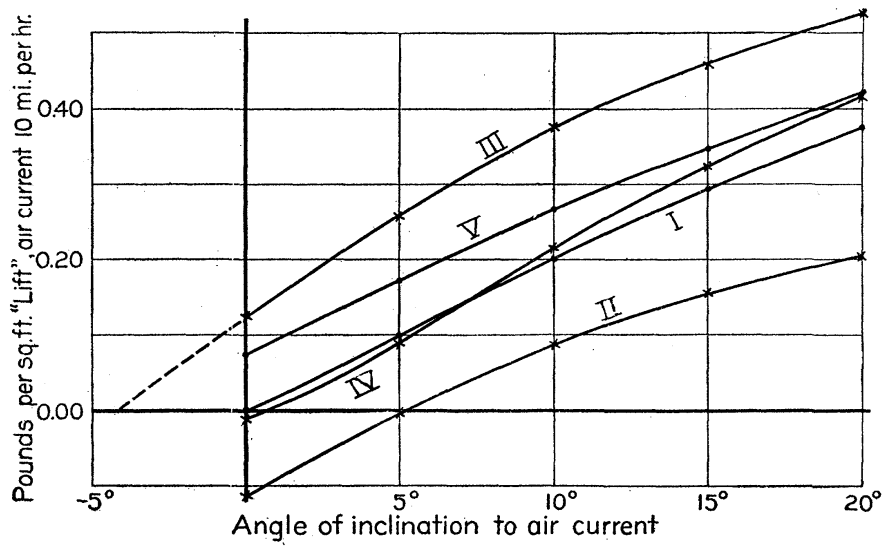

Fig. 6.

in Fig. 6, the average of several readings for each inclination of the aëroplane being used to determine several points on the curves. 
[VOL. XXIV.

It will be noted that the comparative ${ }^{1}$ lift of Type V. at small angles is slightly greater than at large angles, by comparison with any of the other four types.

It will also be noted that the best "lift" (per se) is given by the single curvature surface, concave on the under side, and the poorest by the single curvature surface, convex on the under side; but, in selecting the best form of aëroplane, for use in an aerodyne, other factors enter as will be seen when these results are considered in connection with the "drift" and center of pressure experiments.

\section{"Drift" Experiments.}

The apparatus for measuring the "drift" (or horizontal component of the air-pressure) was mounted in such a way that the center of the aerroplane was one foot from the free end of the box and exactly in the middle of the opening.

Fig. 7 shows a side elevation and Fig. 8 an end elevation of this

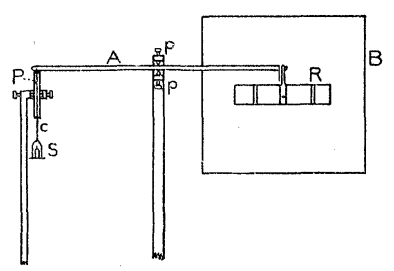

Fig. ?.

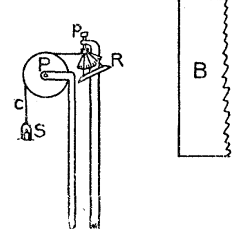

Fig. 8.

apparatus, which is simply a balance arm, $A$, mounted on vertical pivots, $p p$, with the aëroplane, $R$, mounted on one arm and with the other arm attached to a cord, $C$, passing over a frictionless pulley, $P$. The scale-pan, $S$, in this case, being attached to the other end of the cord and the "drift" being measured by the adjustment of weights on the scale-pan.

As in the case of the "lift" experiments the aëroplane, $R$, was successively placed at $0^{\circ}, 5^{\circ}, 10^{\circ}, 15^{\circ}$ and $20^{\circ}$ and the correspond-

1 The writer has taken out patents in the United States, Canada, Great Britain, Germany and France on Types IV. and V., but by an oversight on the part of the patent attorneys the word "comparative" in referring to the lift of Type V. was omitted from a part of the description rendering the explanation of action absurd as there is no known form of aëroplane which will give a greater lift at a smaller angle, for ordinary angles between zero and thirty degrees. 
ing weights to make a balance, when the air current was passing, were recorded. For each reading the "drift" of the arm without the plane was subtracted from the reading, I might mention here that a compound balance. (such as was used by Maxim in his experiments) for obtaining both the "lift" and "drift" with the same apparatus was first tried, but the method of employing separate pieces of apparatus for each form of experiment was found to be far more sensitive and accurate.

The data of the experiments on "drift" are plotted in Fig. 9, and on comparing them with the "lifts" of Fig. 6 we have some interesting results. It is noted that the single curvature surface (Type III.) concave on the under side, not only has the largest

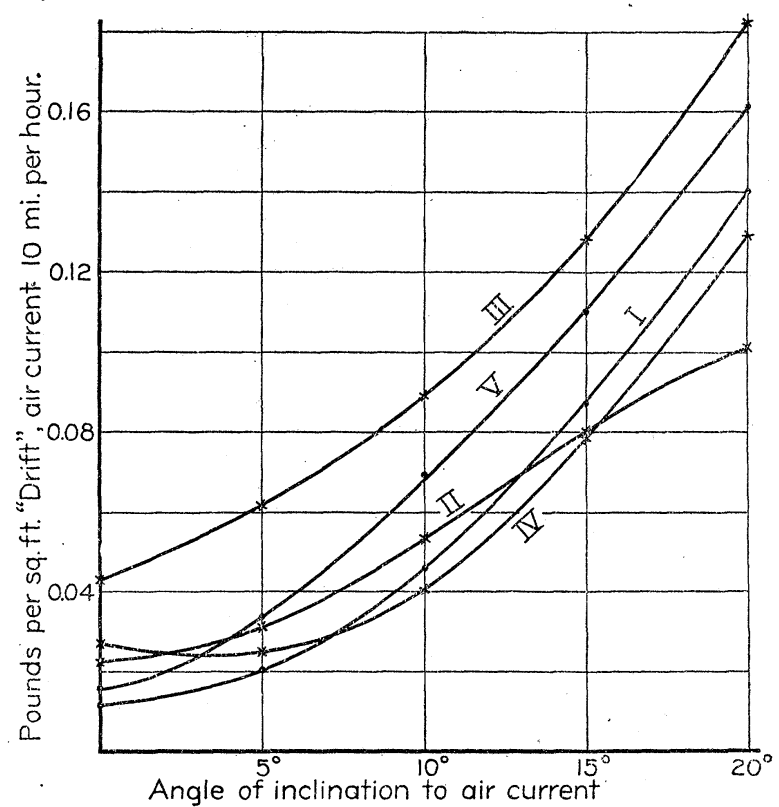

Fig. 9.

"lift," but also the largest " drift," while the "drift" for Type IV. (concave in front, convex in the rear, on the under side) actually decreases from $0^{\circ}$ to $4^{\circ}$. For equal drifts we have the table given in the second following section and from this table we see that for equal "drifts" Type IV. at $10^{\circ}$ has more than double the "lift" of Type III. at $-0.7^{\circ}$. This fact has more than usual interest, be- 
cause it will be shown in the next section of this paper that Type IV. has automatic longitudinal stability from $90^{\circ}$ to $0^{\circ}$, while Type III. has longitudinal instability between the angles of $28^{\circ}$ and $0^{\circ}$.

The decreasing drift of Type IV. between the angles of $0^{\circ}$ and $4^{\circ}$ has also something to do with the soaring of birds, in the opinion of the writer, but this will be further referred to in another section.

In the two foregoing sections the writer has measured only the vertical component of air resistance ("lift") and the horizontal component of air resistance ("drift"). I have not followed Lilienthal's ${ }^{1}$ method of plotting a resultant force (the total air resistance) from the "lift" and "drift" and afterwards resolving this resultant into a "normal" and "tangential" force; for these latter mainly apply in the case of an aëroplane falling through the air at the same time moving forwards along a course at a certain negative angle with the horizontal.

While Lilienthal's method is interesting when applied to his assumed slope of a bird's wing during the down-stroke, it is applicable only to artificial flight when it is sought to solve that problem by beating wings and it is, in general, not applicable to the problem of artificial flight with fixed aëroplanes driven horizontally through the air at a certain positive angle of inclination.

\section{Center of Pressure.}

Thorough in many ways as Lilienthal's results on "lift" and "drift" are, he unfortunately passed all too lightly over the more important question of the center of pressure, and while Joessel, Kummer and Langley experimented on this all essential problem, their experiments, invariably stopped short of those critical angles between $25^{\circ}$ and $0^{\circ}$ which are by all means the important ones in the study of natural and artificial flight.

The first method used by the writer, for measuring the center of pressure, was the usual one of the eccentric plane with counterpoising weight (used by Langley and others, see "Experiments in Aërodynamics," Langley, pp. 89-93, I902) but its decided limitations were soon apparent and a delicate counterpoising spring was 
substituted with excellent results, for aëroplanes whose centers of pressure advance far in front of their centers of figure.

The counterpoising spring is limited however to use with certain aëroplanes between about $35^{\circ}$ and $0^{\circ}$ so that a use of both methods is necessitated for a complete set of readings between $0^{\circ}$ and $90^{\circ}$.

The aerroplanes to be tested were ruled with lines (parallel to the leading edges) at distances of $1 / 2^{\prime \prime}, \mathrm{I}^{\prime \prime}, \mathrm{I} \mathrm{I} / 2^{\prime \prime}$, etc., in front of (and behind) their centers of figure and at the points where these lines reached the side edges of the aëroplanes screw clamps were successively placed. The clamps being provided with pivot-holes for the insertion of the pivots of the supporting frame.

Figs. IO and I I show front and side elevations of the apparatus as employed with counterpoising spring; $M$ being the arm holding the supporting frame, $F . \quad F$ carries small arms which are adjustable

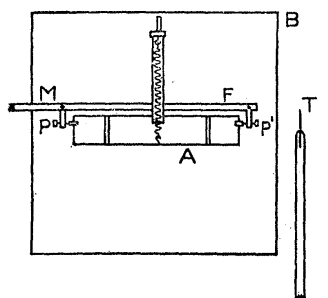

Fig. 10.

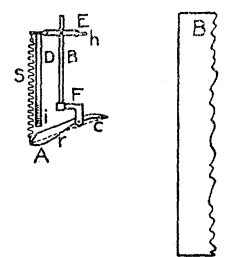

Fig. 11

along its length to allow of use with different widths of aëroplanes, and these small arms carry the pivots, $p p^{\prime}$, which carry the aëroplane under test, $A$. The frame, $F$, also carries a vertical rod, $B$, to which is clamped at any desired height, the block, $E$. $E$ houses a horizontal rod, $H$ (adjustable horizontally), which carries at its end a long sensitive spring, $S$, acting as a counterpoise for the unbalanced weight of $A$.

$S$ is protected from the air-current by a shield, $D(\mathrm{~V}$-shaped in plain cross-section), and a small pointer soldered to $S$ plays over the scale, $i$; near the bottom of $D$.

The dotted line, $C$, Fig. I I, shows the (imaginary) chord of the curvature of $A$ and in every case the upper side of the rib, $r$, is made parallel to this chord so that the angle which $A$ makes with the horizontal may be read by means of a vertically mounted trans- 
parent protractor (shown in Fig. IO at $T$ ) by sighting through the protractor along the upper line of the ribs.

When using the aerroplanes with a counterpoising weight the spring with its accessories was removed and the counterpoise secured by attaching a flat leaden weight to the upper side of the aëroplane under test.

Both methods of experiment were used as the circumstances of each setting of the pivots demanded and where the results of the two methods "overlapped "the accordance of the readings was satisfactory.

I have unfortunately been unable to obtain the original papers of Joessel and Kummer so that I do not know of their methods of experimenting but Langley mounted his counterpoised eccentric planes on the arm of a large whirling table and obtained (from a pencil trace) the angle corresponding to a certain setting of the side pivots and it is just here that the superiority of the method above described (with stationary aëroplanes and artificial air current) is most pronounced, for with several tpyes of aëroplanes (viz.: Types I., III., and V.) there is not one angle but two corresponding to one setting of the side pivots.

To illustrate this, let us take the example of plane No. III., with pivots on the center line; by Langley's method the only reading obtained is that at $90^{\circ}$; by the writer's method the reading for $90^{\circ}$ is also obtained if the plane is untouched, but if the rear edge of the plane is supported loosely between the thumb and forefinger of one hand and carried to a position nearer the horizontal we find a second angle (at $\mathrm{I}_{2} \frac{3}{4}^{\circ}$ ) where, if the plane be slightly depressed, the rear edge will be strongly depressed, and if slightly raised, the rear edge will be strongly raised and we here have a second angle (capable of accurate measurement) where the center of pressure again corresponds to the center of figure. Of course, in place of the thumb and forefinger, a metal yoke with adjustable set screws could be similarly employed and could be vertically raised until this second critical angle was reached, but the thumb and forefinger furnish a sensitive index of the approach to this angle and the accuracy of the results are excellent.

The results of these experiments are given in Fig. I 2 . where 
angles with the horizontal are plotted as abscissæ and centers of pressure (in percentage of the side of plane), both before and behind the center of figure, are ordinates.

In the case of the plane (Type I.) we note that the center of pressure steadily advances in front of the center of figure until the critical angle of $26^{\circ}$ is reached when the center of pressure rapidly

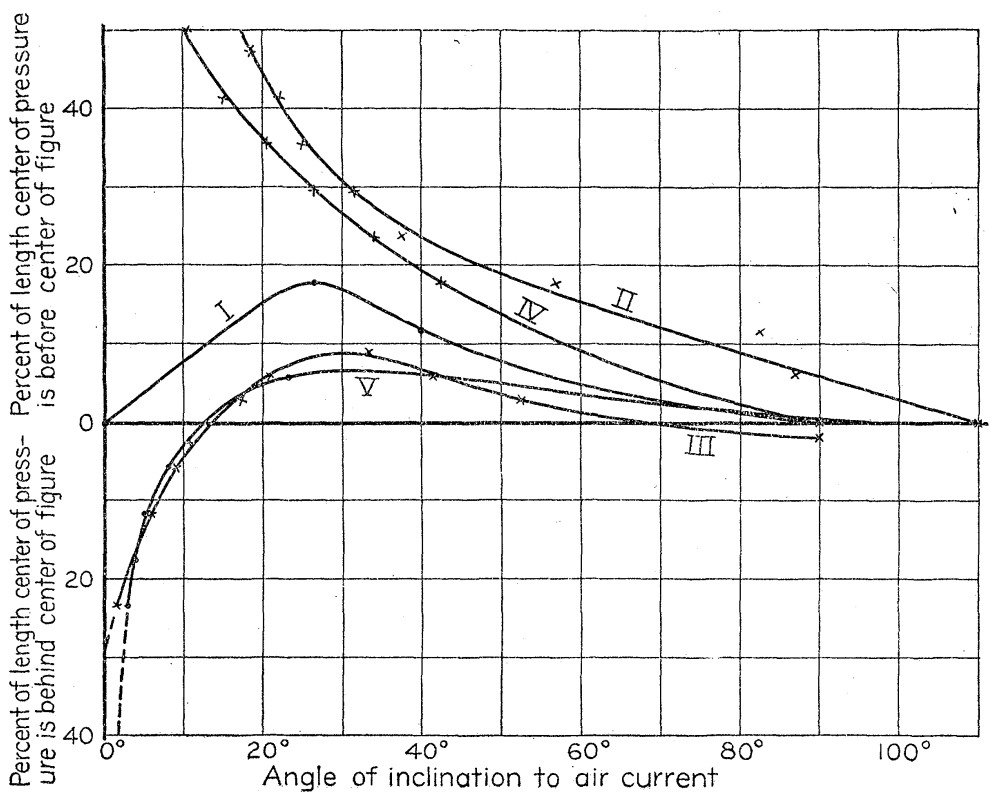

Fig. 12.

retreats to the center of figure as the angle becomes smaller and reaches $0^{\circ}$.

In the cases of Types III. and $\mathrm{V}$. this reversal takes place at somewhat near the same angle but at a much shorter distance in front of the center of figure, the center of pressure then rapidly retreats behind the center of figure which it passes at about $13^{\circ} .^{2}$

1 In the case of a square with $9^{\prime \prime}$ side the writer found this critical angle at about $18^{\circ}$ and it is just about this point where the curves of Joessel, Kummer, and Langley (who all experimented with square planes) cease. Joessel inferring that the law formulated by him, $c=0.3(\mathbf{I}-\sin a) L$ held good until $0^{\circ}$ was reached.

$2 \mathrm{My}$ results for Type III. agree fairly well with those of Spratt who, according to Moedebeck's “'Taschenbuch fur Flugtechniker und Luftschiffer," I904, p. 335, has not made his experiments public. Spratts' results as given by Moedebeck are these: for a single concave curvature surface of $\frac{1}{12}$ curvature (shape not stated) the center of pressure 
[Vol. XXIV.

Type III., on account of its excellent " lifting" qualities, is the aëroplane that has been almost universally used in artificial flight experiments, but this reversal in the position of the center of pressure with its consequent utter lack of longitudinal stability is doubtless responsible for nearly all the accidents that have occured in aerroplane experiments, Lilienthal and Pilcher lost their lives through ignorance of this reversal and Langley's large machine was also probably wrecked through a lack of knowledge on this point.

For Types II. and IV. we have the remarkable result that the center of pressure steadily advances to the forward edge of the plane, where, by reference to Fig. 6 , we note that the lifts are both negative. We therefore have, for these two types, the condition of automatic longitudinal stability for all positive angles and "lifis."

Significance of These Results for Artificial Fligh's.

In comparing the relative merits of these five types from the viewpoint of artificial flight, we must not only take into consideration their stability curves as shown in Fig. I 2 , but also compare the "lifts" and "drifts" as given in Figs. 6 and 9.

We then find that for the two aëroplanes of automatic stability Type IV. has a much superior "lift" to Type II. and a lesser "drift" between the angles of $2^{\circ}$ and $15^{\circ}$; which are the important ones for artificial flight.

As pointed out above, Type III. has been almost exclusively used in artificial flight, but when it is compared to Type IV. we see that it has an utter lack of stability while Type IV. has automatic stability and while, at first sight, Type III. has the superior lifting qualities it also has a large "drift." As a matter of fact the "lift" of Type IV., as compared to its "drift," is superior to the "lift" of Type III., as compared to its "drift," for certain angles as per the table below, in which the respective values of "lift," at their corresponding angles, are given for equal "drifts" in each case.

\footnotetext{
at $0^{\circ}$ lies near the rear side, it advances as the angle increases passing the middle point at about $17^{\circ}$ and advances to about $8 \frac{1}{2}$ per cent. from the center of figure at $30^{\circ}$. It then moves in the opposite direction until it reaches the center of figure at $90^{\circ}$.

1 Ahlborn, "Illus. Aeron. Mitteilungen, 1904. States that only slightly convex aëroplanes (Type II. of the writer's experiments) possess unconditional automatic stability, but his statement seems to be based on incomplete observations rather than on experiments.
} 


\begin{tabular}{c|c|c|c|c}
\hline \multicolumn{2}{c|}{ Type IV. } & \multicolumn{2}{c|}{ Type III. } & Lift IV. $\div$ Lift III. \\
\cline { 1 - 2 } Angle. & Lift. & Angle. & Lift. & Ratio. \\
\hline $20^{\circ}$ & .417 & $15.1^{\circ}$ & .459 & .91 \\
19 & .400 & 13.7 & .439 & .911 \\
18 & .381 & 12.4 & .416 & .916 \\
17 & .364 & 11.1 & .395 & .921 \\
16 & .346 & 9.6 & .368 & .941 \\
15 & .325 & 8 & .331 & .982 \\
14 & .303 & 6.5 & .297 & 1.020 \\
13 & .283 & 4.6 & .249 & 1.136 \\
12 & .261 & 2.9 & .204 & 1.280 \\
11 & .240 & 1 & .154 & 1.558 \\
10 & .216 & -0.7 & .105 & 2.055 \\
\hline
\end{tabular}

From this table it appears that for equal drifts, Type IV. at $10^{\circ}$ has actually double the lifting value of Type III. at $-0.7^{\circ}$.

Lilienthal's principle for artificial flight was certainly well taken, viz.: "Stability first, propulsion afterwards" but we cannot review the history of experimental aëronautics without insisting on this revision: Automatic stability first and always propulsion so soon as prime-movers become sufficiently light.

Aëroplanes of Type IV. give the essential elements of automatic longitudinal stability; the well established principles of the "dihedral angle" and keels give automatic transverse stability ; and gas engines, now approaching 3 pounds per horsepower give the required lightness of prime movers.

In these three principles, therefore, the problem of aërial navigation is theoretically solved. It now remains only to so combine these three essentials, in practical form, to solve the problem from an engineering standpoint.

I could hardly insist that aëroplanes of Type IV. are the only ones possessing the all important properties of automatic stability but among simple aëroplanes (i.e., those having zero, single, or double curvature), my laboratory experiments have clearly shown that Type IV. is the only aëroplane having at the same time automatuc longitudinal stability combined with excellent lifting properties and exceedingly small drifting properties, for all angles that would probably be utilized in artificial flight. 
Significance of These Results to Natural Fight.

Lilienthal in his valuable book ${ }^{1}$ has given an able analysis of bird flight, but he has made one assumption (page 76) which is hardly tenable, viz.: that the slightly concave surface is the form most like that of the bird's wing.

Neither my experiments nor a general consideration of the structure of the bird's wing lead to this conclusion.

The average cross-section of a birds wing when extended consists essentially of a forward portion, $A$, Fig. I 3 , of rigid formation, with a central portion, $B$, of partial rigidity, and a rear portion, $C$, of extreme flexibility.

While this formation certainly varies from the portion nearest the body to the extreme tip of the wings, I think it will be generally conceded that Fig. I 3 fairly represents an average crossectiosn of an average bird's wing (during

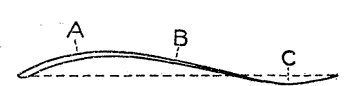

Fig. 13. the down stroke).

If now we conceive this wing in rapid up-and-down strokes passing through a resisting medium, such as the air, it requires only a rudimental conception of mechanics to infer that in the up stroke the cross-section assumes the form shown in $A C$, Fig. I4, while in the down stroke a form similar to that shown in $A C$, Fig. 15 , would be necessitated.

In each figure, $o p$, gives the direction of the wing motion in each

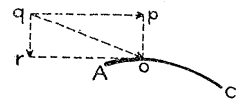

Fig. 14.

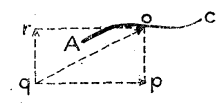

Fig. 15.

case, while or represents the absolute direction of the air current. It is obvious that the relative movement of the air particles is roughly represented by $q o$ and it is equally obvious that a wing, of the type described in connection with Fig. I 2 , would be forced into the approximate forms shown in Figs. I4 and I 5 - corresponding to the two Types II. and IV. both of which have been shown by the laboratory experiments to have automatic longitudinal stability.

If then we accept this reasoning, it is proven that in bird flight

1 “ Der Vogelflug als Grundlage der Fliegekunst," Berlin, 1889. 
the two forms assumed by the wing both have automatic longitudinal stability, that in the up stroke the "lift" (negative in this case) is a minimum (see Type II., Fig. 6) while the "drift" is small (see Type II., Fig. 9) and that in the down stroke the "lift" is excellent (see Type IV., Fig. 6) while the "drift" is a minimüm (see Type IV., Fig. 9).

From this it is seen that the laboratory experiments are in full accord and give a most rational explanation of the wonderful properties displayed in the flight of a bird.

For soaring or sailing flight the most probable form of the bird's wing is that shown in Fig. I 6 which is simply a less accentuated form of Fig. I 5, due to the lessened air pressure on the under side of the wing.

The resolution of forces as shown in this figure gives a perfectly rational explanation of soaring flight, by which a bird is supported and at the same time advances against an ascending current of air, for in working out the "lift" and "drift" under these conditions we find that $O R$, the resultant, is in advance of the normal to the chord of the double curvature,

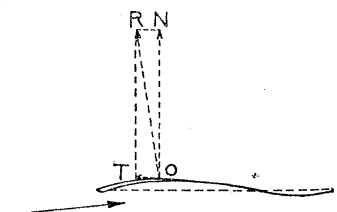

Fig. 16. and we have for the forces acting upon the surface the vertical component $O N$ equal to the weight of the bird and the tangential force, $O T$, which furthers, instead of hinders, the advance against the air current.

It has been frequently shown by delicate anemometer measurements, etc., that no natural wind is steady but that the natural air currents have a pulsating movement, with pulsations varying sometimes several times in a second. The soaring bird can instinctively feel these pulsations and can make excellent use of them by slightly inclining the extended wings more or less to the pulsating current and can thus maintain or increase its height while at the same time it slowly advances against the air current.

Experiments from many sources (Lilienthal and others) have shown that there is also in natural winds, near the surface of land or water, an ascensional trend of about $3^{\circ}$ and this further facilitates the soaring of most birds. 
Referring again to the automatic stability of birds, the extended tail in many species is undoubtedly a valuable auxiliary to the maintenance of automatic longitudinal stability; but it is quite evident from a consideration of several species in which the tail is almost lacking ( $e . g$., the wild duck) that the tail is not essential, and this further accentuates the idea that the primal and main cause of automatic stability in bird flight is to be found in the wing-forms shown in Figs. I4 and I 5.

Lilienthal's close adherence to his conception of the natural wing form was the probable cause of his death, for in all of his soaring machines (and in a great majority of soaring machines that have since been built) the single concave surface has alone been used and with it of necessity (see Curve III., Fig. I2), automatic stability is impossible and "stability" is only obtainable by the agility of the operator in moving his body or an auxiliary steering aëroplane.

The Influence of an Underplane.

In considering the subject of aëroplanes used in artificial flight it occurred to the writer that the lifting properties of aëroplanes might

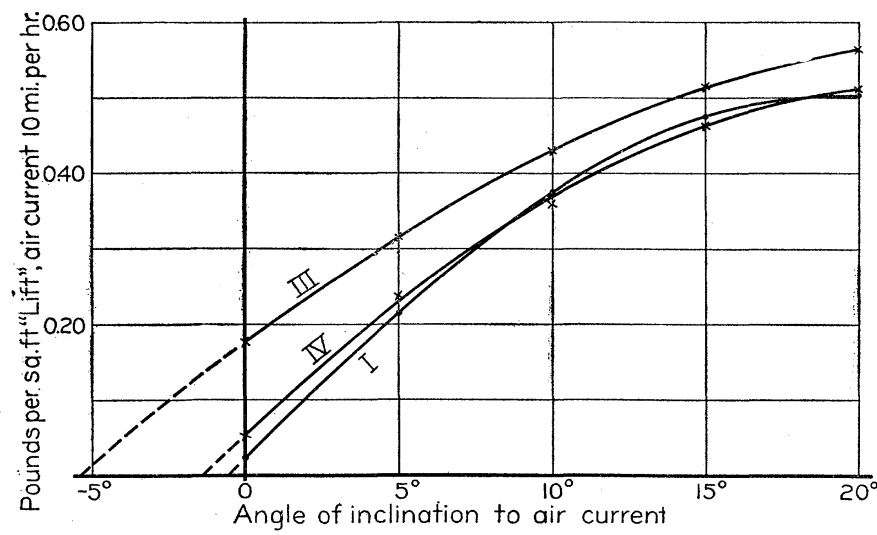

Fig. 17.

be considerably increased by allowing the aëroplanes to skim close to an underplane such as a level piece of land or close over water.

As is shown in Fig. I 7, a considerable increase in "lift" really occurs (due no doubt to the wedging action and consequent compression between the aëroplane and underplane) and at first sight 
it would seem a valuable consideration in the design of an aërodyne ; since it is just when arising and alighting, when the speed would be comparatively low, that the maximum "lift" would be desired. However, many other modifying conditions must be considered, since screw propellers must have a considerable diameter and their central line of thrust must be in line with the aerroplane resistance; and, moreover, the "drift" is also considerably increased with an underplane and the center of pressure is shifted, in general, considerably farther "aft" than it would be in free flight, introducing serious difficulties in balancing. These various drawbacks of the underplane may be overcome ( $e . g$., by superimposed planes), but it is well to draw attention to them.

In Fig. I 7 the "lift" curves, with an underplane, are given for Types I., III., and IV. The readings with the underplane were obtained with the apparatus shown in Figs. 4 and 5 under the same conditions as before, but with an underplane (a large drawing board) placed horizontally one half inch below the rear edge of the aëroplane in its mean position of balance.

It is needless here to go into details concerning the influence of an underplane on the "drift" and center of pressure of aeroplanes, but the writer's experiments with "lifts" may be summarized as follows: (I) With plane surfaces (Type I.) and double curvature surfaces (Types IV. and V.) the relative increases of "lifts" with an underplane are greater than in the case of single curvature surfaces. (2) Under certain conditions the lift may be nearly doubled by an underplane very close to the rear edge, but in general, the influence nearly disappears at a distance above the underplane equal to about one third the length (in the direction of the air current) of the aëroplane.

In conclusion, with regard to the general design of a practical aërodyne, I can only say that the proportion of parts is an essential feature which must be worked out by outdoor experiments, preferably over a sheet of water.

The laboratory experiments, described in this paper, can give but little help in the proportioning of parts, but they clearly show the type of aëroplane to be adopted and the type to be distinctly avoided. On the one hand we have Type IV., with its great advantages of 
automatic longitudinal stability, excellent lifting properties and exceptionally low "drift" and on the other hand the long-adopted aëroplane with single concave curvature, which, while it has most superior lifting qualities, has also a most serious "drift" (for high speeds particularly to be considered) and above all in importance, most treacherous longitudinal stability.

A trifle in added speed gives the former type equal "lift" with the latter (since the lift and drift increase with the square of the speed), so that it should be an easy matter for a designer to choose unhesitatingly between the two.

RoTHESAY, N. B., CANADA, October זo, 1906. 